\title{
Effectiveness and Productivity Improvement of Conventional Pultrusion Processes
}

\author{
Evgeny Barkanov *, Pavel Akishin (D) and Endija Namsone-Sile
}

Citation: Barkanov, E.; Akishin, P.; Namsone-Sile, E. Effectiveness and Productivity Improvement of Conventional Pultrusion Processes. Polymers 2022, 14, 841. https:// doi.org/10.3390/polym14040841

Academic Editors: Frederic Lortie, Jannick Duchet-Rumeau and Jean-François Gérard

Received: 12 January 2022

Accepted: 18 February 2022

Published: 21 February 2022

Publisher's Note: MDPI stays neutral with regard to jurisdictional claims in published maps and institutional affiliations.

Copyright: (C) 2022 by the authors. Licensee MDPI, Basel, Switzerland. This article is an open access article distributed under the terms and conditions of the Creative Commons Attribution (CC BY) license (https:// creativecommons.org/licenses/by/ $4.0 /)$.
Institute of Materials and Structures, Riga Technical University, 1 Kalku Street, LV-1658 Riga, Latvia; pavels.akisins@rtu.lv (P.A.); endija.namsone@inbox.lv (E.N.-S.)

* Correspondence: barkanov@latnet.lv; Tel.: +371-67089264

\begin{abstract}
Pultrusion is a technological process in which fibers impregnated with resin move through the heated die and solidify into a composite profile with a constant cross section, as in the metallic die. The effectiveness and productivity of conventional pultrusion processes, preserving the quality of pultruded profiles, could be improved by process optimization or by the application of new, effective heating sources instead of electrical resistances with high heat losses. Due to the large dimension of the numerical problem and multiple iterations applied for the solution of government equations, an optimization methodology was developed, using the method of experimental design and the response surface technique. To develop microwave-assisted pultrusion processes, as well as pultrusion tooling design and process control, new effective electromagnetic-thermo-chemical finite element models and algorithms were developed by using general-purpose finite element software that results in considerable savings in development time and costs and makes available various modeling features of the finite element packages. The effectiveness and productivity of the optimized conventional pultrusion processes and the developed microwave-assisted pultrusion processes are estimated in comparison with the real pultrusion processes used in laboratory and industrial shops.
\end{abstract}

Keywords: pultrusion; finite element simulation; optimization; microwave heating; effectiveness; productivity

\section{Introduction}

Pultrusion is an automated technological process for the production of high-quality composite profiles with a constant cross section after the fibers' impregnation with a resin and their movement through a heated metallic die [1]. The effectiveness and productivity of conventional pultrusion processes, reducing the cost of profiles, could be increased by process optimization or by the application of a new, effective heating source with less energy losses than those in present industrial processes.

Earlier, optimization problems were studied for a limited number of design parameters [2-6]. Later, the application of artificial neural networks, together with genetic algorithms $[7,8]$, and planning of experiments and surrogate-based methodology $[9,10]$ allowed increasing the number of investigated design parameters and solving more complicated optimization problems. A short review on the optimization of pultrusion processes can be found in [11]. However, in most optimization problems, steady-state thermo-chemical simulations are executed that do not allow estimation of the effectiveness of pultrusion processes with temperature control. Due to the limited number of optimization studies and some simplifications followed in numerical models, describing real pultrusion processes, the development of a more accurate and realistic optimization strategy; the examination of ambient room temperature, as an additional design parameter; and the use of a heater switch-on and switch-off strategy are required.

Among all possible heating methods, a high-frequency electromagnetic energy source [12] characterized by fast, instantaneous, non-contact, and volumetric heating can be examined 
as the best choice for pultrusion applications. It is necessary to note that now it is successfully used in industrial curing processes [13-16], and microwave-assisted pultrusion processes are analyzed only experimentally [17-19]. A limited number of studies [20,21] published recently on the simulation aspects of microwave-assisted pultrusion processes have slowed down their development. For this reason, new, reliable electromagneticthermo-chemical finite element models and algorithms were developed in this study by using the general-purpose finite element software ANSYS.

\section{Optimization of Conventional Pultrusion Processes}

Since it is necessary to operate with numerical problems of large dimension and considerable time is required for the solution of coupled thermo-chemical problems, an optimization methodology was developed using the method of experimental design [22] and the response surface technique [23] (Figure 1). In our case, distribution of the optimization variables in the design space was previously unknown. For this reason, the experimental plan with as regular as possible distribution of the points of experiments in the domain of factors was built in the first stage. Then, in each point of the plan of experiments, the coupled thermo-chemical problem was solved by the mixed time integration scheme and nodal control volume method [24]. This approach was validated successfully in an experimental trial by using cure sensors for the measurement of electrical resistivity and temperature on the profile surface [25]. More accurate and realistic process optimization was achieved with the algorithm developed in [26] and by allowing the temperature control executed by the heater switch-on and switch-off strategy. In the third stage, approximations were built using a conventional un-weighted least squares estimation with the elimination of some points [27], and polynomial functions with the first, second, and third orders were estimated in their applicability to describe the response surfaces. Finally, the constrained non-linear optimization problem was solved by the application of a new version of the random search method [28] and the generalized reduced gradient algorithm [29].



Figure 1. Optimization procedure.

The objective function in the present optimization problems describes the effectiveness of pultrusion processes and minimizes the electrical energy $(E)$ necessary for the production of a pultruded profile with the length of $1 \mathrm{~m}$ :

$$
E=\frac{n_{\text {heater }} \cdot W_{\text {heater }} \cdot k_{r t}}{m_{\text {profile }} \cdot V_{\text {pull }}} \rightarrow \min ,
$$

where $n_{\text {heater }}$ is the number of heaters, $m_{\text {profile }}$ is the number of simultaneously produced profiles, $W_{\text {heater }}$ is the power of the electrical heater, $V_{\text {pull }}$ is the process pull speed, and $k_{r t}=t_{\text {work }} / t_{\text {process }}$ is the relative time of the heaters' work during the manufacturing process [30], determined as the ratio between the time $t_{\text {work }}$, when the electrical heaters are switched on, and the full process time or simulation time, $t_{\text {process }}$. In general, the following variables are taken as the design parameters: pull speed $V_{\text {pull }}$, location of heaters $X_{\text {heater }}$, control temperature on heaters $T_{\text {cont }}$, and ambient room temperature $T_{\text {room }}$.

To achieve qualitative profile production, when the resin was fully cured, there was no overheating during the pultrusion process and it did not flow from the die, the following 
constraints were introduced: $\alpha \geq 0.95, T \leq T_{\max }$, and $\alpha_{\text {surf }}^{\text {exit }} \geq 0.7$, where $\alpha=H(t) / H_{t r}$ is the degree of cure, $H(t)$ is the amount of heat evolved during the curing up to time $t, H_{t r}$ is the total heat of reaction, $T$ is the temperature, $T_{\max }$ is the maximal allowable temperature, and $\alpha_{\text {surf }}^{\text {exit }}$ is the degree of cure on the profile surface at die exit.

The developed methodology was successfully applied for optimization of conventional pultrusion processes, producing profiles with different cross sections (Figure 2) and made of glass fibers and the following thermoset resins: polyester C-L ISO 112G, vinyl ester Crystic VE 676-03 [31], and epoxy Resoltech 1401+1407+AC140 [32]. The thermal properties of corresponding tool materials (Table A1) were taken from the handbooks and datasheets, but the properties of composite materials (Table A2) were measured experimentally with the lamped properties evaluated by the rule of mixtures [24]:

$$
\begin{gathered}
\bar{\rho}=\left(1-V_{r}\right) \rho_{f}+V_{r} \rho_{r} \\
\bar{c}=\frac{\left(1-V_{r}\right) \rho_{f} c_{f}+V_{r} \rho_{r} c_{r}}{\bar{\rho}} \\
\bar{k}=\frac{k_{f} k_{r} \bar{\rho}}{\left(1-V_{r}\right) \rho_{f} k_{r}+V_{r} \rho_{r} k_{f}},
\end{gathered}
$$

where $\rho, c$, and $k$ are the density, specific heat, and thermal conductivity, respectively; $V$ is the volume fraction; and indexes $f$ and $r$ relate to the fibers and resin, respectively.

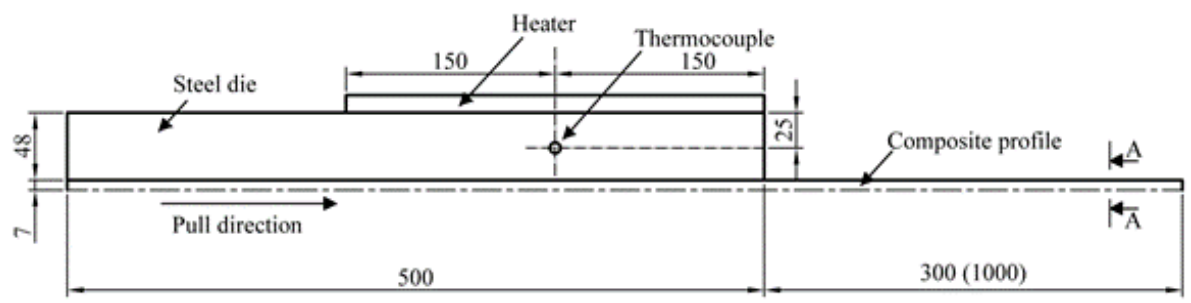

(a)

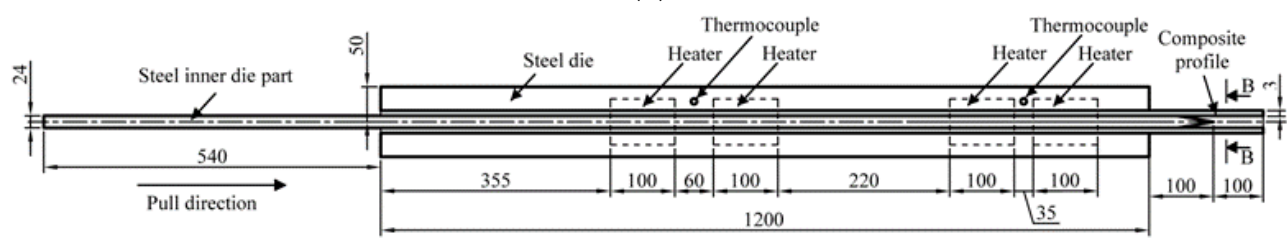

(b)

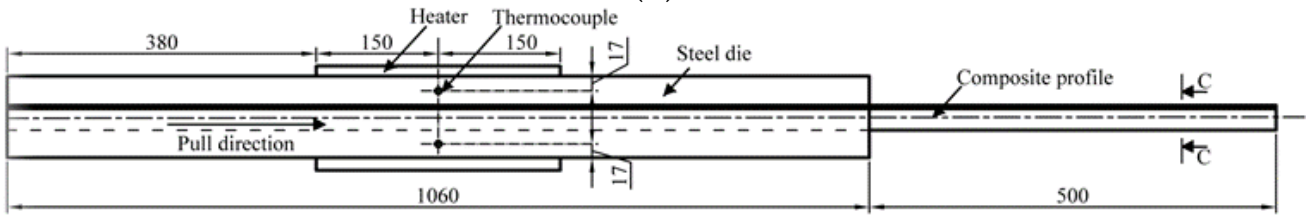

(c)
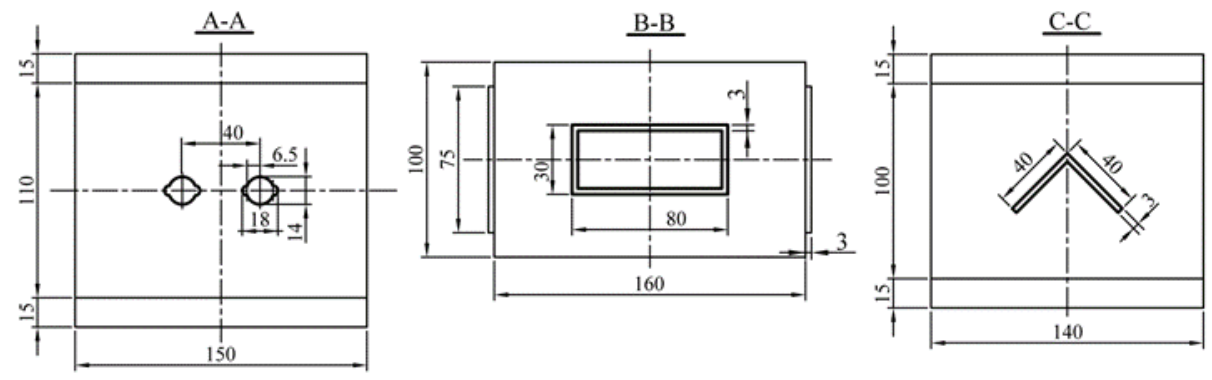

Figure 2. Schemes of pultrusion processes for (a) rod with ears profile, (b) thin-walled rectangular profile, and (c) corner profile. 
To describe the rate of resin reaction, the Kamal-Sourour curing kinetic model [33-35], which in the best way approximates the results of differential scanning calorimetry (DSC) tests, was chosen:

$$
\frac{d \alpha}{d t}=\left(K_{1} \exp \left(-\frac{E_{1}}{R T}\right)+K_{2} \exp \left(-\frac{E_{2}}{R T}\right) \cdot \alpha^{m}\right) \cdot(1-\alpha)^{n},
$$

where $R=8.314 \mathrm{~J} / \mathrm{mol} \cdot \mathrm{K}$ is the universal gas constant, $K_{1}$ and $K_{2}$ are the frequency factors, $E_{1}$ and $E_{2}$ are the activation energies, and $n$ and $m$ are the orders of the reaction. It is necessary to note that the Kamal-Sourour reaction model combines autocatalytic behavior with an $n$-th-order reaction model and besides the first rate constant $K_{1} \exp \left(-E_{1} / R T\right)$ and the exponent $n$ describe the $n$-th-order reaction and the second rate constant $K_{2} \exp \left(-E_{2} / R T\right)$ and the exponent $m$ express the autocatalytic contribution of the reaction. To define the curing kinetic parameters given in Table A3, results of DSC scans performed by Mettler Toledo on samples heated from room temperature to $250{ }^{\circ} \mathrm{C}$ at rates of 2,5 , and $10^{\circ} \mathrm{C} / \mathrm{min}$ and the least squares method fitting the experimental heat flow curves were used.

Optimal results are presented in Table 1 for minimal and maximal ambient temperatures in the industrial shop. It is obvious that all processes were considerably effective for the highest ambient room temperature. For this reason, it is impossible to ignore the effect of ambient temperature on optimization problems of pultrusion processes. The availability of a real technological map for the process producing two rod profiles with ears and operating with a pull speed of $20 \mathrm{~cm} / \mathrm{min}$ and a control temperature of $135^{\circ} \mathrm{C}$ on electrical heaters made it possible to estimate the process effectiveness and productivity. Its energy consumption is given also in Table 1 in square brackets for different ambient shop temperatures. It was seen now that with an application of the developed optimization methodology, the pull speed of this technological process increased by 2.0-2.3 times and the energy consumption reduced by 1.37-1.49 times per $1 \mathrm{~m}$ of pultruded profile in dependence on the ambient temperature in the industrial shop.

Table 1. Results of optimization for different temperatures in the industrial shop.






\section{Development of Microwave-Assisted Pultrusion Processes}

Innovative microwave-assisted pultrusion processes can be described by the following coupled electromagnetic-thermo-chemical problem:

$$
\left\{\begin{array}{c}
\rho c \frac{\partial T}{\partial t}-\frac{\partial}{\partial x}\left(k_{x} \frac{\partial T}{\partial x}\right)-\frac{\partial}{\partial y}\left(k_{y} \frac{\partial T}{\partial y}\right)-\frac{\partial}{\partial z}\left(k_{z} \frac{\partial T}{\partial z}\right)-Q_{c d}=0 \\
\bar{\rho} \bar{c}\left(\frac{\partial T}{\partial t}+u \frac{\partial T}{\partial x}\right)-\frac{\partial}{\partial x}\left(\bar{k}_{x} \frac{\partial T}{\partial x}\right)-\frac{\partial}{\partial y}\left(\bar{k}_{y} \frac{\partial T}{\partial y}\right)-\frac{\partial}{\partial z}\left(\bar{k}_{z} \frac{\partial T}{\partial z}\right)-q-Q_{c o m p}=0 \\
\left(\frac{\partial \alpha}{\partial t}+u \frac{\partial \alpha}{\partial x}\right)=R_{r}
\end{array}\right.
$$

where $\rho$ and $c$ are the density and specific heat of the tooling materials, respectively; $k_{x}$, $k_{y}$, and $k_{z}$ are the thermal conductivities of the tooling materials in $x, y$, and $z$ directions, respectively; $u$ is the pull speed; $\bar{\rho}$ and $\bar{c}$ are the lumped density and specific heat for the composite material, respectively; $\bar{k}_{x}, \bar{k}_{y}$, and $\bar{k}_{z}$ are the lumped thermal conductivities of the composite material in $x, y$, and $z$ directions, respectively; $R_{r}$ is the rate of the resin reaction; $q$ is the generative term related to the internal heat generation due to the exothermic resin reaction; $Q_{c o m p}$ is the absorbed energy field in the composite material; and $Q_{c d}$ is the absorbed energy field in the ceramic die, taken into account only for high dielectric losses of the ceramic material. It is necessary to note that the first equation in Equation (4) presents the energy equation for the tool; second, the energy equation for the composite moving in the pull direction; and third, the species or transport equation for the resin. The energy and transport equations are coupled since an exothermic heat release term appears in the energy equation of the moving composite.

The absorption energy fields were determined solving the well-known Maxwell's equations [12] by the following expression:

$$
Q=2 \pi f \varepsilon_{0} \varepsilon^{\prime \prime} E_{r m s}^{2}
$$

where $f$ is the microwave frequency, $\varepsilon_{0}$ is the vacuum permittivity, $\varepsilon^{\prime \prime}$ is the loss factor of electric permittivity, and $E_{r m s}$ is the root mean square of the electric field. The system of Equation (4) was solved in ANSYS by the developed algorithm presented in Figure 3. The effectiveness of the microwave heating in pultrusion processes was estimated later as follows:

$$
Q_{\%}=\frac{\sum_{i=1}^{N} Q_{i} V_{i}}{P_{M W}} \cdot 100 \%,
$$

where $Q_{i}$ is the energy absorbed in the $i$-th finite element, $V_{i}$ is the volume of the $i$-th finite element, $P_{M W}$ is the energy of the microwave heating source, and $N$ is the number of finite elements used for the modeling of the ceramic die or composite.

To demonstrate the effectiveness and productivity of microwave-assisted pultrusion processes in comparison with conventional processes, the technological process producing a rod profile with a diameter of $16 \mathrm{~mm}$ and made of polyester resin POLRES 305BV [36] and glass fibers 4800 tex with a resin mass fraction of $26 \%$ was examined. The corresponding thermal material properties are given in Tables A1 and A2, the kinetic parameters of the resin in Table A3, and the dielectric properties of materials in Table A4, where $\mu_{r}$ is the relative permeability, $\varepsilon_{r}^{\prime}$ is the relative permittivity, $\varepsilon_{r}^{\prime \prime}$ is its loss factor, and $R_{0}$ is the resistivity. The innovative pultrusion setup for microwave heating (Figure 4) consisted of a steel die and a microwave block attached to the die. This block included the ceramic inlet made of boron nitride and a waveguide. For the generation of microwaves, a magnetron with a frequency of $2.45 \mathrm{GHz}$ was used. The distribution of temperature and the degree of cure along the profile for the ambient room temperature of $17^{\circ} \mathrm{C}$, a pull speed of $100 \mathrm{~cm} / \mathrm{min}$, an applied energy of $0.85 \mathrm{~kW}$, and time of $30 \mathrm{~min}$ from the process start are 
presented in Figures 5 and 6, respectively. The energy consumption of the process in this case was equal to $14.2 \mathrm{~W} / \mathrm{m}$.

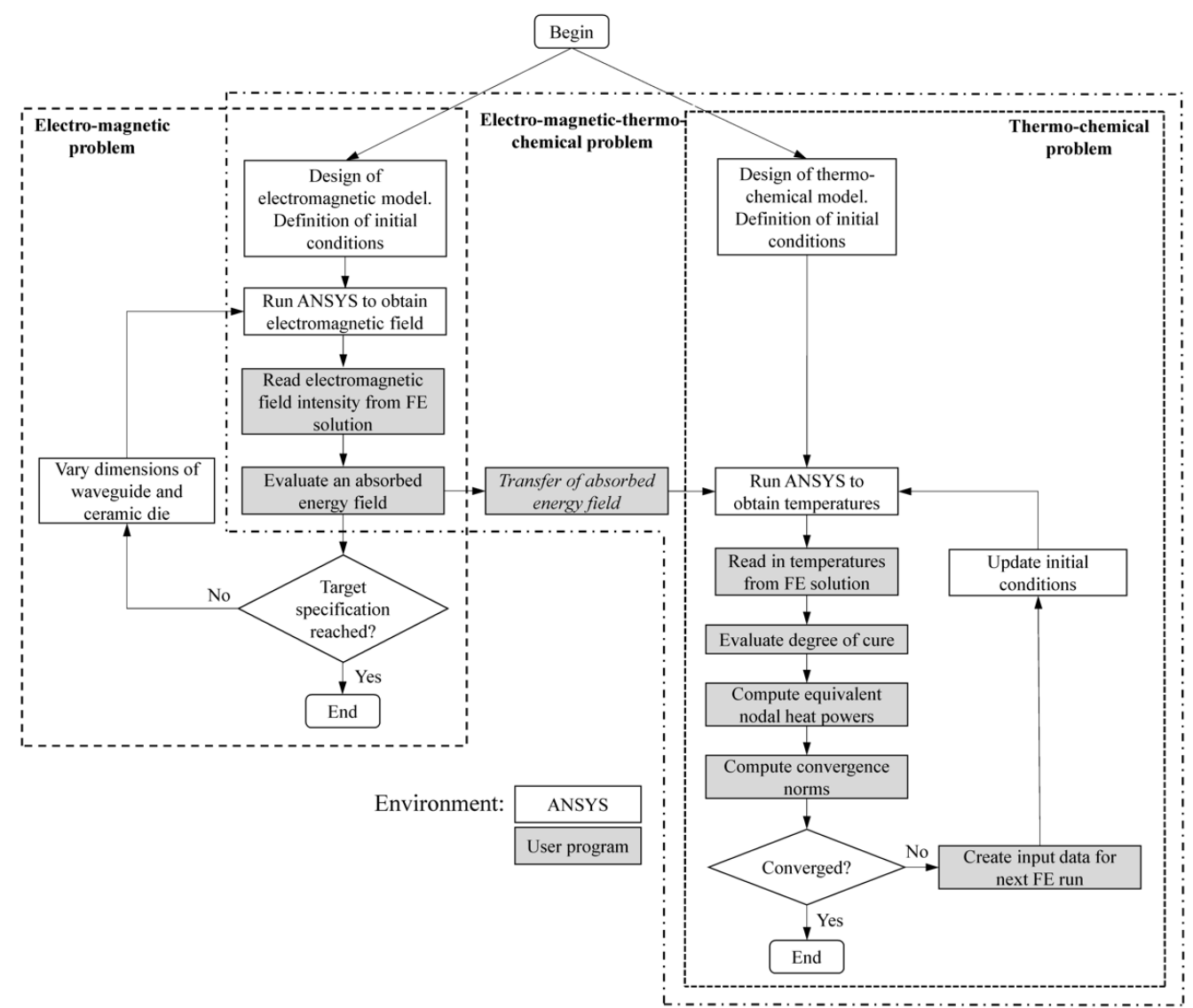

Figure 3. Electromagnetic-thermo-chemical algorithm for a simulation of microwave-assisted pultrusion processes.

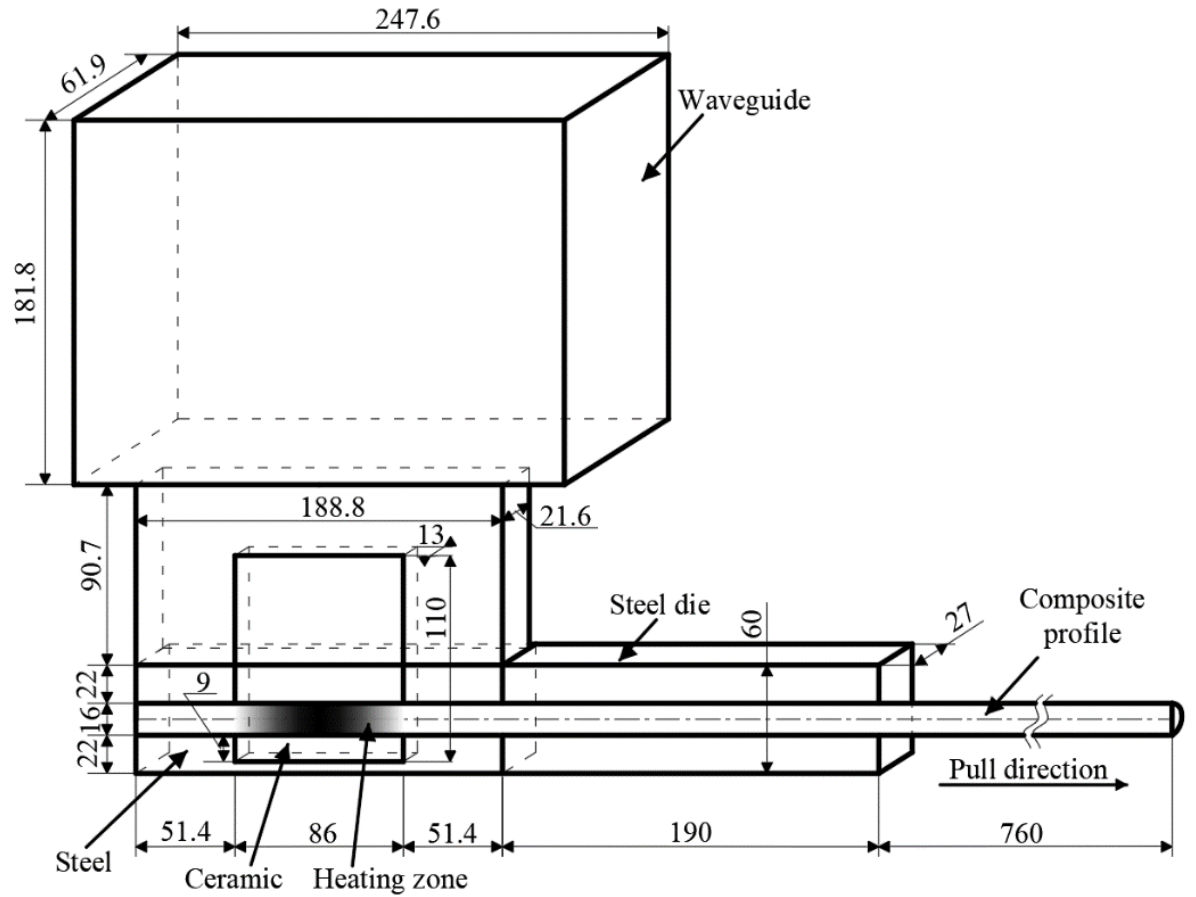

Figure 4. Scheme of microwave-assisted pultrusion process (symmetry used). 


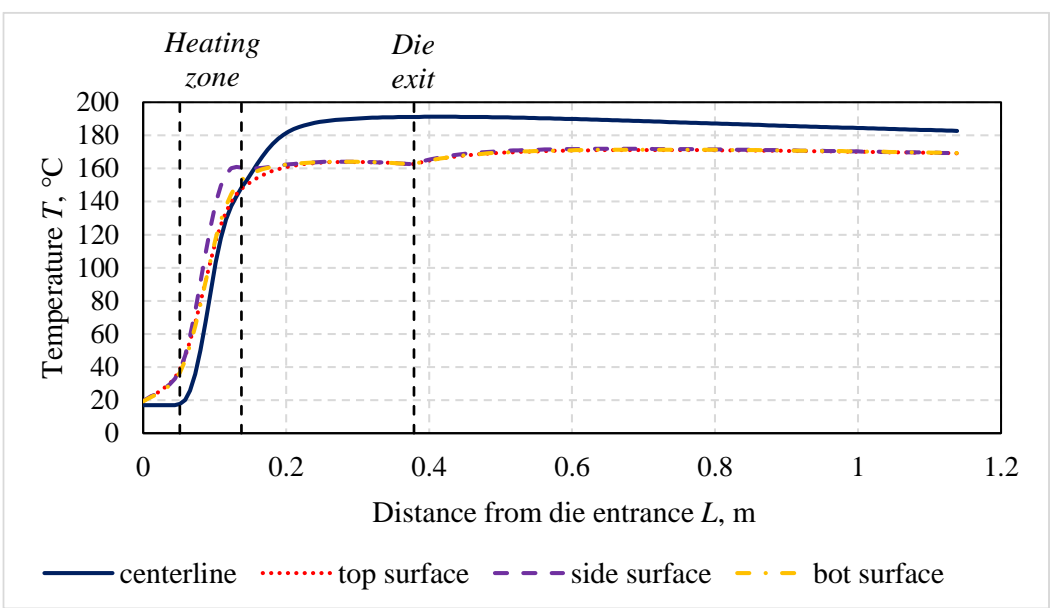

Figure 5. Distribution of temperature along the profile.

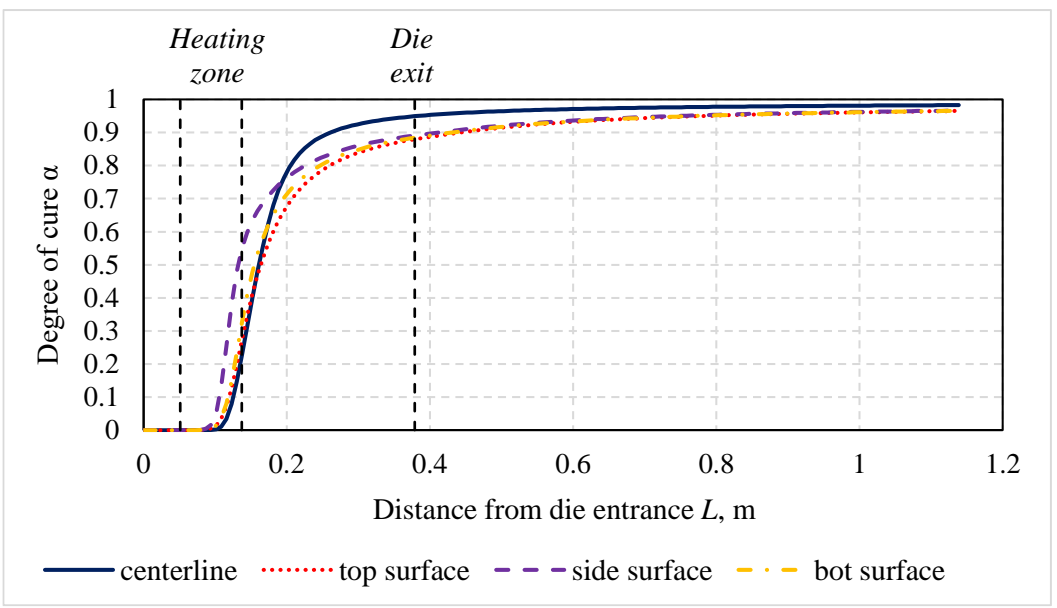

Figure 6. Distribution of the degree of cure along the profile.

The numerical study demonstrated that the pull speed of the developed innovative process was higher by 5.6 times and the energy consumption was lower by 1.7 times in comparison with the real conventional process performed at a pull speed of $18 \mathrm{~cm} / \mathrm{min}$ with an energy consumption of $24.8 \mathrm{~W} / \mathrm{m}$ and described in detail in [26]. It is necessary to note that the high effectiveness and productivity of microwave-assisted pultrusion processes were obtained by preserving the high quality of pultruded profiles and without optimization. The application of optimization could improve these values additionally.

\section{Conclusions}

The application of the developed non-direct optimization methodology based on the planning of experiments and the response surface technique and holistic simulation tools developed for the design of innovative microwave-assisted pultrusion processes allowed increasing considerably the effectiveness and productivity of existing conventional pultrusion processes operating in industrial and laboratory shops.

Author Contributions: Supervision, conceptualization, methodology, writing, E.B.; Conceptualization, formal analysis, methodology, investigation, P.A.; Formal analysis, investigation, visualization, E.N.-S. All authors have read and agreed to the published version of the manuscript.

Funding: This research was funded by the European Regional Development Fund (ERDF), project no. 1.1.1.1/18/A/053, "An Effectiveness Improvement of Conventional Pultrusion Processes".

Institutional Review Board Statement: Not applicable. 
Informed Consent Statement: Not applicable.

Data Availability Statement: The data presented in this study are available on request from P.A.

Conflicts of Interest: The authors declare no conflict of interest.

\section{Appendix A}

Table A1. Thermal properties of tool materials.

\begin{tabular}{lcccc}
\hline \multicolumn{1}{c}{ Property } & $\begin{array}{c}\text { Steel } \\
\text { (Conventional Die) }\end{array}$ & $\begin{array}{c}\text { Aluminum } \\
\text { (Heater) }\end{array}$ & $\begin{array}{c}\text { Steel } \\
\text { (Advanced Die) }\end{array}$ & $\begin{array}{c}\text { Boron Nitride } \\
\text { (Ceramic Die) }\end{array}$ \\
\hline$\rho\left(\mathrm{kg} / \mathrm{m}^{3}\right)$ & 7720 & 2700 & 7850 & 2100 \\
$c(\mathrm{~J} /(\mathrm{kg} \cdot \mathrm{K}))$ & 470 & 896 & 460 & 960 \\
$k(\mathrm{~W} /(\mathrm{m} \cdot \mathrm{K}))$ & 43 & 180 & 33 & 35 \\
\hline
\end{tabular}

Table A2. Thermal properties of composite materials.

\begin{tabular}{|c|c|c|c|c|c|c|c|c|c|}
\hline \multirow{2}{*}{ Property } & \multirow{2}{*}{ Tex 4800} & \multicolumn{2}{|c|}{ C-L ISO 112G } & \multicolumn{2}{|c|}{ Crystic VE 676-03 } & \multicolumn{2}{|c|}{$\begin{array}{c}\text { Resoltech } \\
\text { 1401+1407+AC140 }\end{array}$} & \multicolumn{2}{|c|}{ Polres 305BV } \\
\hline & & $\begin{array}{l}\text { Phys. } \\
\text { (Resin) }\end{array}$ & $\begin{array}{l}\text { Lumped } \\
\text { (Composite) }\end{array}$ & $\begin{array}{l}\text { Phys. } \\
\text { (Resin) }\end{array}$ & $\begin{array}{l}\text { Lumped } \\
\text { (Composite) }\end{array}$ & $\begin{array}{l}\text { Phys. } \\
\text { (Resin) }\end{array}$ & $\begin{array}{l}\text { Lumped } \\
\text { (Composite) }\end{array}$ & $\begin{array}{l}\text { Phys. } \\
\text { (Resin) }\end{array}$ & $\begin{array}{l}\text { Lumped } \\
\text { (Composite) }\end{array}$ \\
\hline$\rho\left(\mathrm{kg} / \mathrm{m}^{3}\right)$ & 2500 & 1100 & 1953 & 1100 & 1564 & 1200 & 1992 & 1100 & 1870 \\
\hline$c(\mathrm{~J} /(\mathrm{kg} \cdot \mathrm{K}))$ & 1235 & 1360 & 1263 & 1190 & 1214 & 1300 & 1264 & 1360 & 1268 \\
\hline$k_{x}(\mathrm{~W} /(\mathrm{m} \cdot \mathrm{K}))$ & 11 & 0.209 & 0.890 & 0.188 & 0.392 & 0.214 & 0.475 & 0.209 & 0.750 \\
\hline$k_{y}(\mathrm{~W} /(\mathrm{m} \cdot \mathrm{K}))$ & 1 & 0.209 & 0.546 & 0.188 & 0.330 & 0.214 & 0.382 & 0.209 & 0.500 \\
\hline$T_{\max }\left({ }^{\circ} \mathrm{C}\right)$ & & \multicolumn{2}{|c|}{160} & \multicolumn{2}{|c|}{160} & \multicolumn{2}{|c|}{185} & \multicolumn{2}{|c|}{200} \\
\hline
\end{tabular}

Table A3. Kinetic parameters of resins.

\begin{tabular}{lcccc}
\hline \multicolumn{1}{c}{ Property } & C-L ISO 112G & $\begin{array}{c}\text { Crystic VE } \\
\mathbf{6 7 6 - 0 3}\end{array}$ & $\begin{array}{c}\text { Resoltech } \\
\mathbf{1 4 0 1 + 1 4 0 7 + A C 1 4 0}\end{array}$ & Polres 305BV \\
\hline$H_{t r},(\mathrm{~J} / \mathrm{kg})$ & 223,385 & 270,105 & 334,093 & 323,074 \\
$K_{1}\left(\mathrm{~s}^{-1}\right)$ & $2.6 \times 10^{13}$ & $2.98 \times 10^{11}$ & $3.03 \times 10^{11}$ & $14,289,310,986$ \\
$K_{2}\left(\mathrm{~s}^{-1}\right)$ & $1.2 \times 10^{12}$ & $6.10 \times 10^{11}$ & 12,000 & 285.870 \\
$E_{1}(\mathrm{~J} / \mathrm{mol})$ & 116,769 & 110,865 & 104,845 & 85,573 \\
$E_{2}(\mathrm{~J} / \mathrm{mol})$ & 200,000 & 93,241 & $2,000,000$ & 33,141 \\
$n$ & 1.27 & 1.63 & 0.79 & 2.342 \\
$m$ & 0.0011 & 1.01 & 0.001 & 0.519 \\
\hline
\end{tabular}

Table A4. Dielectric properties of materials.

\begin{tabular}{lcccc}
\hline \multicolumn{1}{r}{ Property } & Composite & Air & Boron Nitride & Steel \\
\hline$\mu_{r}$ & 1 & 1 & 1 & 1 \\
$\varepsilon^{\prime} r_{r}$ & 5.7 & 1 & 3.0 & 1 \\
$\mathcal{\varepsilon}^{\prime \prime}{ }_{r}$ & 0.32 & 0 & 0.0001 & - \\
$R_{0}(\Omega)$ & - & $\infty$ & - & 0 \\
\hline
\end{tabular}

\section{References}

1. Goldsworthy, W.B. Apparatus for Producing Elongated Articles from Fiber-Reinforced Plastic Material. U.S. Patent US2871911 A, 2 February 1959.

2. Li, J.; Joshi, S.C.; Lam, Y.C. Curing optimization for pultruded composite sections. Compos. Sci. Technol. 2002, 62, $457-467$. [CrossRef]

3. Carlone, P.; Palazzo, G.S.; Pasquino, R. Pultrusion manufacturing process development: Cure optimization by hybrid computational methods. Comput. Math. Appl. 2007, 53, 1464-1471. [CrossRef]

4. Lam, Y.C.; Li, J.; Joshi, S.C. Simultaneous optimization of die-heating and pull-speed in pultrusion of thermosetting composites. Polym. Compos. 2003, 24, 199-209. [CrossRef] 
5. Joshi, S.C.; Lam, T.C.; Tun, U.W. Improved cure optimization in pultrusion with pre-heating and die-cooler temperature. Compos. Part A Appl. Sci. Manuf. 2003, 34, 1151-1159. [CrossRef]

6. Coelho, R.M.L.; Calado, V.M.A. An optimization procedure for the pultrusion process based on a finite element formulation. Polym. Compos. 2002, 23, 329-341. [CrossRef]

7. Wilcox, J.A.D.; Wright, D.T. Towards pultrusion process optimization using artificial neural networks. J. Mater. Process. Tech. 1998, 83, 131-141. [CrossRef]

8. Chen, X.; Xie, H.; Chen, H.; Zhang, F. Optimization for CFRP pultrusion process based on genetic algorithm-neural network. Int. J. Mater. Form. 2010, 3, 1391-1399. [CrossRef]

9. Tutum, C.C.; Deb, K.; Baran, I. Constrained efficient global optimization for pultrusion process. Mater. Manuf. Process. 2015, 30, 538-551. [CrossRef]

10. Tutum, C.C.; Baran, I.; Deb, K. Optimum design of pultrusion process via evolutionary multi-objective optimization. Int. J. Adv. Manuf. Tech. 2014, 72, 1205-1217. [CrossRef]

11. Safonov, A.A.; Carlone, P.; Akhatov, I. Mathematical simulation of pultrusion processes: A review. Compos. Struct. 2018, 184, 153-177. [CrossRef]

12. Metaxas, A.C.; Meredith, R.J. Industrial Microwave Heating; IEEE Power Engineering, Series 4; Peter Peregrinus Limited: London, UK, 1983.

13. Thostenson, E.T.; Chou, T.-W. Microwave and conventional curing of thick-section thermoset composite laminates: Experiment and simulation. Polym. Compos. 2001, 22, 197-212. [CrossRef]

14. Liu, L.; Yi, S.; Ong, L.S.; Chian, K.S.; Osiyemi, S.; Lim, S.H.; Su, F. Chemothermal modelling and finite-element analysis for microwave cure process of underfill in flip-chip packaging. IEEE Trans. Electron. Packag. Manuf. 2005, 28, 355-363. [CrossRef]

15. Li, Y.; Li, N.; Zhou, J.; Cheng, Q. Microwave curing of multidirectional carbon fiber reinforced polymer composites. Compos. Struct. 2019, 212, 83-93. [CrossRef]

16. Jeon, S.; Kim, J.; Yang, D. Design of Large-Scale Microwave Cavity for Uniform and Efficient Plastic Heating. Polymers 2022, 14, 541. [CrossRef]

17. Lin, M.; Hawley, M.C. Preliminary tests of the application of continuous microwave technique to pultrusion. In Proceedings of the 38 International SAMPE Symposium and Exhibition, Advanced Materials: Performance Through Technology Insertion, Volume 38, Book 2, Anaheim, CA, USA, 10-13 June 1993; Bailey, V., Janicki, G.C., Haulik, T., Eds.; SAMPE: Anaheim, CA, USA, 1993; pp. 436-446.

18. Smith, A.C.; McMillan, A.M.; Hawley, M.C. Microwave pultrusion of graphite/epoxy composites using single frequency and variable frequency processing techniques. In Proceedings of the 30 International SAMPE Technical Conference, Materials-the star at center stage, Vol. 30, San Antonio, TX, USA, 20-28 October 1998; Wilson, B.A., Hunter, B.J., May, R., Ciements, L.L., Eds.; SAMPE: Covina, CA, USA, 1998.

19. Methven, J.M.; Ghaffariyan, S.R.; Abidin, A.Z. Manufacture of fiber-reinforced composites by microwave assisted pultrusion. Polym. Compos. 2000, 21, 586-594. [CrossRef]

20. Carlone, P.; Palazzo, G.S. Numerical modelling of the microwave assisted pultrusion process. Int. J. Mater. Form. 2008, 1, 1323-1326. [CrossRef]

21. Barkanov, E.; Akishin, P.; Emmerich, R.; Graf, M. Numerical simulation of advanced pultrusion processes with microwave heating. In Proceedings of the VII European Congress on Computational Methods in Applied Sciences and Engineering, Volume IV, Crete, Greece, 5-10 June 2016; Papadrakakis, M., Papadopoulos, V., Stefanou, G., Plevris, V., Eds.; National Technical University: Athens, Greece, 2016; pp. 7720-7738. [CrossRef]

22. Wu, C.F.J.; Hamada, M. Experiments: Planning, Analysis, and Parameter Design Optimization; John Wiley \& Sons: New York, NY, USA, 2000.

23. Myers, R.H.; Montgomery, D.C. Response Surface Methodology: Process and Product Optimisation Using Designed Experiments; John Wiley \& Sons: New York, NY, USA, 2002.

24. Barkanov, E.; Akishin, P.; Miazza, N.L.; Galvez, S. ANSYS-based algorithms for a simulation of pultrusion processes. Mech. Adv. Mater. Struct. 2017, 24, 377-384. [CrossRef]

25. Barkanov, E.; Akishin, P.; Miazza, N.L.; Galvez, S.; Pantelelis, N. Experimental validation of thermo-chemical algorithm for a simulation of pultrusion processes. J. Phys. Conf. Ser. 2018, 991, 012009. [CrossRef]

26. Barkanov, E.; Akishin, P.; Namsone, E.; Bondarchuk, A.; Pantelelis, N. Real time characterization of pultrusion processes with a temperature control. Mech. Compos. Mater. 2020, 56, 135-148. [CrossRef]

27. Auzins, J.; Janushevskis, A.; Janushevskis, J.; Skukis, E. Software EDAOpt for experimental design, analysis and multiobjective robust optimization. In Proceedings of the 1st International Conference on Engineering and Applied Sciences Optimization, Kos, Greece, 4-6 June 2014; National Technical University: Athens, Greece, 2014; pp. 101-123.

28. Janushevskis, A.; Akinfiev, T.; Auzins, J.; Boyko, A. A comparative analysis of global search procedures. Proc. Est. Acad. Sci. Eng. 2004, 10, 236-250.

29. Lasdon, L.S.; Fox, R.L.; Rather, M.W. Nonlinear optimization using the generalized reduced gradient method. Rev. Fr. Automat. Infor. 1974, 8, 73-103. [CrossRef]

30. Barkanov, E.; Akishin, P.; Namsone, E.; Auzins, J.; Morozovs, A. Optimization of pultrusion processes for an industrial application. Mech. Compos. Mater. 2021, 56, 697-712. [CrossRef] 
31. SCOTT BADER Crystic VE 673-03 Datasheet. Available online: http:/ /jp.scottbader.com/uploads/files/4690_crystic-ve676-0 3pa-resin-en-feb13.pdf (accessed on 9 February 2022).

32. Resoltech 1400-1407 Datasheet. Available online: https://www.resoltech.com/en/markets/1400-detail.html (accessed on 9 February 2022).

33. Akishin, P.; Barkanov, E.; Miazza, N.; Galvez, S. Curing kinetic models of resins for microwave assisted pultrusion. Key Eng. Mater. 2017, 721, 92-96. [CrossRef]

34. Namsone, E.; Arshanitsa, A.; Morozovs, A. Analysis of curing kinetic models for polyester resin C-L ISO 112 G. Key Eng. Mater. 2020, 850, 70-75. [CrossRef]

35. Franieck, E.; Fleischmann, M.; Hölck, O.; Kutuzova, L.; Kandelbauer, A. Cure kinetics modeling of a high glass transition temperature epoxy molding compound (EMC) based on inline dielectric analysis. Polymers 2021, 13, 1734. [CrossRef]

36. OMAR Industrias. POLRES Polyester Resins. Product Catalogue. Available online: http://www.sappec-dz.com/sites/default/ files/Catalogue_Industrias_Omar_Resines.pdf (accessed on 9 February 2022). 